\title{
LA MIRADA DURA: \\ 17 NOTAS SOBRE 17 MONUMENTOS DE JONATHAN PEREL
}

\author{
POR \\ JuAn Besse \\ Universidad de Buenos Aires • Universidad Nacional de Lanús
}

\section{ENTRADA}

El escrito que sigue hace cuerpo en 17 notas. 17 notas para un comentario sobre 17 monumentos, la película de Jonathan Perel. ${ }^{1}$ Se basa en las notas originales que escribí para comentar la película, las cuales se vieron unas veces interpeladas, puestas en entredicho por las preguntas y las controversias que surgieron durante el debate tras el estreno y otras veces surcadas por el trabajo de barruntar frases frente a un auditorio. La escritura que finalmente se presenta aquí no recoge la abigarrada riqueza, ni los argumentos, ni los matices de algunas de las intervenciones como tampoco las respuestas y los silencios que el mismo Perel ofreciera a los interrogantes planteados. En cambio, queriendo ser fiel al primer impulso que me llevó a redactar las notas, sí he incorporado pensamientos que pudieron hilarse tanto en la situación de la proyección como durante el debate en el IDES. Es claro entonces cuánto debe la reescritura de las notas a la situación de pensar entre otros, con otros y contra otros. También, y al sólo efecto de hacer accesible el acervo teórico en el que se filian las ideas aquí vertidas, he agregado citas textuales y referencias bibliográficas concernientes a las 17 notas.

\section{17 NOTAS}

\section{Uno. Con el adjetivo cauteloso.}

17 monumentos (2012) es el nombre que Perel le puso al filme. Antes de 17 monumentos filmó el cortometraje Los murales (2011) y el largometraje El predio (2010).

\footnotetext{
1 Fue la invitación a comentar el filme de Jonathan Perel, en el marco de las actividades del Grupo "Espacios, lugares y marcas territoriales de la violencia política y la represión estatal" del Núcleo de Estudios sobre Memoria del Instituto de Desarrollo Económico y Social (IDES), con sede en Buenos Aires, lo que diera lugar a estas notas.
} 
En los nombres-sustantivos de esos trabajos hay un no uso -cuando no un rechazo-del adjetivo que, según Barthes en El grano de la voz, es la categoría lingüística más pobre que, si abandonada por la ciencia, queda a merced de la ideología. Además, para Barthes, la lengua no siempre permite decidir entre la unicidad contingente de un individuo y la unicidad necesaria de una idea (Milner, El paso 19). En rigor, al escuchar o leer como título "el predio", no sabemos si se trata de un predio en particular, el predio de la ex ESMA o de la idea del predio. En cambio, con 17 monumentos la unicidad contingente, la serie 17 monumentos, pero también de cada uno de los 17 monumentos, parece dicha desde el vamos: son 17 los monumentos o señales que hasta el momento de la filmación se habían emplazado en el territorio argentino. ${ }^{2}$

\section{Dos. Otros 17: el 17 como número-nombre.}

Más allá de lo evidente: ¿Habrá sido el azar lo que condujo al director hacia el nombre 17 monumentos? Me atengo a la decisión de la titulación. Y lo hago porque Jonathan Perel habla la lengua de los argentinos. Para un peroniano y lacanista (peronista y lacaniano) el número 17 no pasa desapercibido. Adosado a octubre dice "lealtad", adosado a noviembre "militancia". 17 de octubre y 17 de noviembre: dos nombres de la política que mueven las aguas quietas y turbulentas, a la vez, de 17 monumentos y 17 monumentos. $^{3}$ ¿Qué es lo propio de un nombre? Entre otros atributos, un nombre se define como nombre por su carácter divisor (Milner, Claridad). El nombre-número 17 , cuando se asocia a octubre, divide.

\section{Tres. El número 17, número-frontera.}

17, un número-frontera que establece el fin de la edad de la inocencia. Volver a los 17 dice la canción de Violeta Parra, es volver a la edad fronteriza entre la mayoría y la minoría de edad.

2 Tal como reza la página web de la Red Federal de Sitios de Memoria (REFESIM)/Archivo Nacional de la Memoria, Secretaría de Derechos Humanos, Ministerio de Justicia y Derechos Humanos de la Presidencia de la Nación: "La Red Federal de Sitios de Memoria es un organismo estatal interjurisdiccional que, con la coordinación del Archivo Nacional de la Memoria, articula las políticas nacionales, provinciales y municipales de memoria e investigación que se llevan adelante en los ex centros clandestinos de detención y otros espacios vinculados con el terrorismo de Estado en todo el país". <http://anm.derhuman.jus.gov. $\mathrm{ar} /$ sitios memoria.html>.

3 La movilización popular del 17 de octubre de 1945 es considerada el momento mítico-fundacional del peronismo, y desde entonces ese día es denominado como Día de la Lealtad. El 17 de noviembre de 1972, luego de 18 años de exilio, Perón retornó a la Argentina. En las efemérides peronistas, y con atención a la militancia política que luchó por su regreso, el 17 de noviembre es el Día de la Militancia.

Revista Iberoamericana, Vol. LXXXI, Núm. 251, Abril-Junio 2015, 657-668 ISSN 0034-9631 (Impreso)

ISSN 2154-4794 (Electrónico) 


\section{Cuatro. Anagramas.}

El nombre 17 monumentos leído anagramáticamente dice 17 mo(nu)mentos. 17 momentos.

Hagamos un desvío por la noción de anagrama para robustecer el nexo monumentomomento. Al investigar el trabajo de Saussure sobre los anagramas -un trabajo en el que el mismo Saussure rozó la rebaba de la locura y por eso veló o no quiso dar a conocer- Starobinski indica que a la hora de analizar la lógica anagramática cabe establecer como presupuesto teórico que cualquier discurso -él dice "todo" discurso- es un conjunto que se presta a la tarea de extracción de un subconjunto. El subconjunto puede ser interpretado, o trabajado, en dos registros: a) entender a esa parte del discurso "como contenido latente o infraestructura del conjunto" y b) "como antecedente del conjunto" (Starobinski 130; énfasis en el original). Atento a esa distinción, propongo avivar el lazo entre ambos registros, y decir que la infraestructura y el antecedente pueden coexistir; también complementarse o 'darse' al lector (o al espectador) a la manera de suplementos y hasta pueden integrarse en una misma estrategia de análisis. Es Saussure el que - enfrascado en su trabajo - discurre acerca de cuestiones terminológicas e instala valores-significados para los términos que utilizará en el análisis anagramático con el fin de hacer florecer sus intuiciones, o descubrimientos, en unidades discursivas más acotadas que las extensas escrituras poéticas o los conglomerados de discursos. Dice, por ejemplo, que:

Anagrama, por oposición a Paragrama, se reservará al caso en que el autor se complazca en concentrar en un pequeño espacio, como el de una palabra o dos, todos los elementos de la palabra-tema, más o menos como en el 'anagrama' según la definición; figura que sólo tiene importancia absolutamente restringida en medio de los fenómenos que se ofrecen al estudio, y no representa en general más que una parte o un accidente del Paragrama. (Saussure, en Starobinski 29)

17 monumentos de Perel propone a través del tedio, como recurso y como efecto, 17 momentos singulares que desmientan el semblante de lo universal empastado con lo genérico, es decir más allá de los invariantes que hacen a la similitud de las señalesmonumentos en lo que respecta a forma, estructura, materiales, coloratura o frases que las constituyen y más allá del tiempo de duración, la misma para cada toma.

Cinco. Universal-singular.

17 monumentos, hace suyo el presupuesto que sostiene que lo universal se manifiesta a través de lo singular, como el paradigma lo hace a través del sintagma. En las puntuaciones que, en Signatura rerum, lleva a cabo Agamben sobre la noción de

Revista Iberoamericana, Vol. LXXXI, Núm. 251, Abril-Junio 2015, 657-668 
paradigma para despejar malentendidos sobre su obra, dice con grave simplicidad que "el paradigma es una forma de conocimiento ni inductiva ni deductiva, sino analógica, que se mueve de la singularidad a la singularidad" (42). Ahora bien, vuelvo sobre el aspecto genérico de los monumentos (formas, colores y leyendas símiles) con el fin de despegarlo de lo universal-singular que los constituye: una historia que es común y a la vez no lo es.

Por una parte, hay un universal clásico, universal fácil, que asocia lo universal con lo cualquiera (Milner Las inclinaciones; Claridad). Se trata del universal comprendido por la lógica paulina del para todo $X$, la cual se expresa en la forma genérica del monumento, la composición de la materialidad física y el texto (casi siempre el mismo) que sólo varía de señal en señal por el nombre propio de cada ex centro, excepto en un caso que no porta nombre y en otros dos que remiten a otras historias de represión y muerte que no son las de los Centros Clandestinos de Detención, Tortura y Exterminio de la última dictadura militar.

Por otra parte, hay también un universal difícil (también siguiendo a Milner), que asocia lo universal con lo "no cualquiera", es decir asociado a lo singular de las tramas locales de la represión y el exterminio político llevado a cabo por el terrorismo de Estado, como diría un discurso muy afín a la propaganda estatal: "a lo largo y a lo ancho del país" pero en cada lugar marcado por los caracteres específicos de las fuerzas represivas actuantes, la escala sociodemográfica, los estilos y operatorias de las diversas militancias, la historicidad de las situaciones en que se gestionó, funcionó, se desmanteló y se quiso borrar la huella de cada CCD (Centro Clandestino de Detención).

Seis. 17 monumentos: uno más uno más uno más uno más...

El tratamiento de los monumentos hace despuntar la cuestión femenina tal como ha sido trabajada por Lacan. Se dice "no" al todo masculino y se propone un abordaje de los monumentos según la lógica del no-todo propia de la cuestión femenina tal como despunta en el modo que la escruta Lacan mediante las fórmulas de la sexuación (Cevasco). Es sabido como Lacan, en uno de sus logion más estruendosos, "La mujer no existe", barre el artículo "La" para enfatizar cuán imposible se revela el universal en lo femenino. La lógica del no-todo que Lacan propone para lo femenino dice entonces que las mujeres, o quienes ocupen ese lugar lógico, son una más una más una más una más una...

Las señales-monumentos a la luz de la cámara de Perel pueden pensarse así: uno + uno + uno + uno hasta contar 17 , no-todos. Un tratamiento que rompe la lógica 
embrionaria del estereotipo y lo hace desmontando la asociación fácil entre lo universal y lo cualquiera. ${ }^{4}$

Siete. El triunfo de la mirada sobre el ojo.

El monumento-señal, cada uno, uno por uno, nos mira. Indicio de esto es que el monumento se sostiene en un tiempo inseparable de la cotidianidad del contexto que lo alberga. Antes que una experiencia de la observación -en el sentido que este término adquiere en el cine documental tomado por el ideal de la ciencia- la película hace a las condiciones de una experiencia de la mirada. Se podría decir que la película no impide, ni rechaza la observación, pero si la propone -sin dudar- lo hace como un segundo momento. Como si Perel dijera: antes de observar, tú, espectador-así lo deseo-requieres constituirte o devenir sujeto de una experiencia de la mirada. ${ }^{5}$

La relación entre el arte, en particular la pintura, y el paisaje es un pasaje necesario a la hora de establecer el corte entre visión y mirada. 17 monumentos explora ese corte. Lo que parece ser una exploración observante de los contextos en los que se emplazan los monumentos-señales, una observación naturalista, es una ingente producción de paisajes constitutivos de la mirada que conecta el presente con el pasado. Así, sondeando en autores que se preocuparon por el encuadre-y, recordemos, Perel produce 17 viñetas, 17 cuadros, de idéntica duración, que se presentan como 17 paisajes con más o menos zoom-Derrida se pregunta “¿qué hace un encuadre? ¿qué deja hacer o qué deja ver?” (Derrida 21). Desde una perspectiva aún más sugerente, Jacques Lis y Gérard Wajcman, en una revisión de la teoría estética que todavía no ha sido lo suficientemente auscultada en su potencia por la teoría social, revisan a la luz de coincidencias con el psicoanálisis

4 Para Dominique Perrot y Roy Preiswerk el estereotipo se compone de dos caras: una simplificación y una generalización. Así estereotipar es generalizar lo simplificado mediante el artilugio de afirmar que quien ve uno ve todos (259).

5 Destaco aquí la utilidad de la distinción entre visión y mirada que nos propone el psicoanálisis de cuño lacaniano. En breves palabras, Lacan señala que podemos ver solamente desde un punto de vista, sin embargo somos mirados desde todos los otros, es decir desde un lugar desde el que no podemos vernos, y aquí va el núcleo del incisivo distingo de Lacan entre visión y mirada: la mirada no es una mirada sino una mirada imaginada por mí en el campo del Otro. En este sentido, estamos frente a una radical desarmonía entre el ojo que ve, o mejor dicho que quiere ver, y la mirada. El momento en el que la mirada -más allá del ojo- se vuelve objeto. Mirada objeto que mancha la transparencia de $m i$ visión particular. A trazo grueso, la distinción entre visión y mirada comenzó a ser desarrollada desde El estadio del espejo (1949), momento en el que Lacan intenta formular los estatutos diferenciales de lo imaginario y de lo simbólico en la constitución del sujeto, pero en rigor, básicamente, lo fue a partir de la teorización que efectúa sobre la pulsión escópica en el El Seminario 11 Los cuatro conceptos fundamentales del psicoanálisis (1964). Un recorrido por la filiación de estas ideas en la obra de Freud puede consultarse en Hervé Huot.

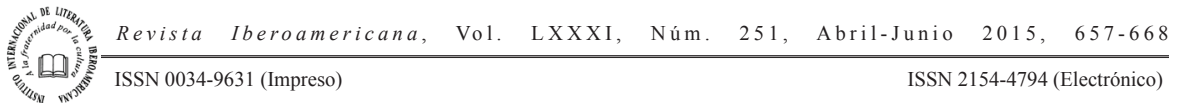


la relación entre el cuadro y lo que se encuentra fuera-de-campo. ${ }^{6}$ Por ejemplo, para François Cheng se trata entonces de "[...] lo que está contenido en el paisaje y lo que lo desborda, lo que es visto y lo que da infinitamente a ver" (Cheng citado en Lis 124). Entre lo "que da infinitamente a ver", la relación entre los sitios de memoria y la vida cotidiana se torna insoslayable, así los monumentos que señalizan los sitios de memoria no escapan a las improntas de los barrios y las regiones en que se localizan.

En Tristes trópicos, Lévi-Strauss traza una semblanza de la relación de la arquitectura con el tiempo en las ciudades americanas, "[... p podría aplicarse la fórmula a la ciudades del Nuevo Mundo: pasan de la lozanía a la juventud pero nunca son antiguas" (81). Sin suscribir a las hipérboles del padre de la antropología estructural, es dable reconocer que en el acotado campo de la señales-memoriales, los cuadros de Perel respiran un decadentismo ominoso, familiares y exóticos a la vez. Velados por el sol o de una cromaticidad agónica por los efectos del cielo nublado, los monumentos decrepitan antes de envejecer. Lo único que se mantiene enhiesto bajo las inclemencias del clima, del sobado urbano o de la cámara de Perel es el lema trinitario e irrevocable: memoriaverdad-justicia.

\section{Ocho. Marcas territoriales.}

Los 17 monumentos son lo que se denomina en la jerga sociológica de los estudios de memoria, y en sentido muy estricto, marcas territoriales. Donde territorial dice de las marcas que son inscripciones no sólo geográficas (en la acepción amplia y laxa del término), sino inscripciones en el territorio en su acepción jurídico-política, las marcas hablan de una política de Estado, de acciones de gobierno en varios niveles, de instituciones públicas de co-gestión entre el Estado y las organizaciones civiles. En ese sentido, la inscripción territorial nada dice de la experiencia del lugar, de cómo se hace lazo con ese recorte en la superficie terrestre, cómo se lo vive o se lo siente a ese mojón emplazado frente a lo que fue y ya no es.

Territorio: inscripción simbólica.

Lugar: lazo imaginario.

Espacio: experiencia real o de lo imposible ("lo que no cesa de no inscribirse").

6 Véanse, entre otros, los análisis de Norman Bryson. Este autor organiza su trabajo subiendo la apuesta teórica lacaniana -aunque a veces desde un historicismo ingenuo no por ello poco fecundo para pensar estos temas-. Norman Bryson, "La pintura Ch'an: mirando un campo que se dilata" en Archipiélago y Norman Bryson, Visión y pintura.

Revista Iberoamericana, Vol. LXXXI, Núm. 251, Abril-Junio 2015, 657-668 ISSN 0034-9631 (Impreso) 


\section{Nueve. Cine militante, cine politico.}

En algún pasaje de El espectador emancipado, escribiendo sobre las paradojas del arte político y sobre la imagen intolerable, Rancière dice que las imágenes del arte político obtenían su poder de los escenarios teóricos que permitían hacer inteligible su contenido y de la fuerza de los movimientos políticos que las engarzaban con una práctica. Ya no es así, y si algo de eso pareciera que se produce de modo análogo a lo que se hacía en los años '60 y '70, hoy, sin duda, sucede de otro modo que no es el del siglo XX. Las imágenes del arte no proporcionan, a modo de un destino, armas para el combate pero sí son parte del movimiento instituyente de las condiciones para el pasaje a nuevos posibles. Hasta aquí un Rancière parafraseado o, con más precisión, refraseado por mí, un poco pour la galerie, porque no suscribo al pie su desazón francesa.

Ahora bien, el llamado cine militante, como participio presente del verbo militar y como atributo calificante de un cine asociado al trabajo político, suele ser pensado como expresión de una experiencia militante. Muchas veces el cine político, en el sentido del cine que toma por objeto lo político, se distancia del cine militante. A veces, arguyendo razones epistemológicas o estéticas, o ambas, trata al cine militante con bajeza. Pienso que hay una tensión inherente al cine político que es la de, por una parte, mostrar-de manera confesa o enmascarada-un trabajo político llevado a cabo mediante prácticas militantes $\mathrm{y}$, por otra parte, tomar distancia de esa experiencia y convertirla en objeto de pensamiento e, incluso, de conocimiento. En 17 monumentos la tentación epistemológica del cineasta se ve expresada en una decisión de método. En la ruta de un autor, Foucault, y en particular de una de sus obras capitales, La arqueología del saber, Perel opta por la vía arqueológica. En la metodología arqueológica propuesta por Foucault la descripción antecede lógicamente a la interpretación como el significante al significado o el representante a lo representado. A eso, y el director lo sabe, no puede escapar el ser hablante.

En 17 monumentos la tensión entre política y militancia no se resuelve sino que se responde. ${ }^{7}$ La película encuentra una respuesta en el estilo elegido: describir, interpretar. No está demás decir que en esa secuencia (descripción-interpretación) que Foucault eleva a la categoría de método, hay toda una política de la lengua que no la supone una superestructura, sino la base material misma del advenimiento de lo humano y que es en sí misma, y por los términos que usa, toda una reconsideración cuando no una recusación del candor epistemológico ingénito al positivismo lógico en su pretensión de verdad sobre el saber.

7 Las resoluciones o soluciones van asociadas a problemas y se ubican en el orden de lo objetivo, en cambio, las respuestas están asociadas a preguntas y se ubican en el orden de los subjetivo (Milner Las inclinaciones).

Revista Iberoamericana, Vol. LXXXI, Núm. 251, Abril-Junio 2015, 657-668 ISSN 0034-9631 (Impreso)

ISSN 2154-4794 (Electrónico) 


\section{Diez. Simplicidad y elegancia.}

La 17 tomas-silentes hacen a la formalización del discurso; sin ellas no habría 17 momentos. Esas 17 formas-cuadro constituyen la condición de una economía matemática para la transmisión de un modo de estar de las señales-monumentos que, de dejarse tomar todas y en todo, por los discursos de la gestión y de la contra-gestión, correría el riesgo de ahogarse en las palabras de las retóricas políticas, académicas, periodísticas o artísticas, por estructura siempre propensas al efecto de cierre de la interpretación. Aunque suene a paradoja describir es abrir un campo perceptivo que distante del concepto, y su afán de significación, abra nuevas preguntas. En la simplicidad la matemática se toca con la inquietud filosófica y, de paso, ordena por (de)mostración.

\section{Once. Al silencio absoluto, la espectralidad silente.}

Los monumentos que rememoran acontecimientos políticos y sucesos atroces suelen morir de banalidad. El trajín cotidiano los invisibiliza y los sume en el silencio. 17 monumentos hace hablar a estas señales de modo particular. Recurre no al silencio absoluto sino a la espectralidad silente para hacerlos hablar. Es evidente que entre los planos fijos de las imágenes y el ruido ambiente hay un corte. Una dislocación deliberada o aceptada por la experiencia que tuvo el director respecto de cada lugar. Imagen y ruidos - que se entreveran con sonidos- están disociados. El espacio que muestra Perel, en una torsión benjaminiana, condensa capas de temporalidad. Las imágenes del monumento dan lugar a la vista de las puertas o los ingresos a los predios de muerte que fueron los ex CCD, frente a los cuales - como pasan en el momento que Perel filma- pasaron incesantes autos, colectivos, camiones, motos, a veces transeúntes. Hay un efecto "imágenes de hoy" y "ruidos del pasado". Imágenes del pasado y ruidos de hoy. El trabajo de la memoria es también eso, acoplar lo que se piensa disjunto y desacoplar lo que se piensa junto.

\section{Doce. Resonancias lanzmannianas.}

"El testigo es el tercer término necesario [junto con el verdugo y la víctima] para que lo inimaginable a la vez encuentre un lugar y haya tenido lugar en esos bosques estúpidos [de Polonia]- Polonia, 'lugar de la nada', como dice Lanzmann" recuerda Gérard Wajcman (228). Perel-17 monumentos y los 17 monumentos como testigo de la señal testificante. Escucho en 17 monumentos "Hay 17 monumentos", "Hay, al menos, no todos los que funcionaron como CCD, 17 lugares de detención y muerte". Allí, donde muchas veces no queda nada de lo que fue el soporte físico de los CCD, allí en ese lugar por donde pasan autos, vecinos, las aves beben y los perros descansan, allí se detuvo, se torturó y se hizo desaparecer.

Revista Iberoamericana, Vol. LXXXI, Núm. 251, Abril-Junio 2015, 657-668 ISSN 0034-9631 (Impreso)

ISSN 2154-4794 (Electrónico) 


\section{Trece. Intranquilidad.}

Me remito a mi experiencia como espectador, a sabiendas de que soy, por los temas que trabajo y por mi propia militancia, un espectador dispuesto. En La arrogancia del presente Jean-Claude Milner, señala y describe -pensando en la década que va de 1965 a 1975- que lo propio de la pequeña burguesía intelectual es producir alboroto, intranquilidad. Que la pequeña burguesía intelectual, por tomar dos ejemplos, en Francia en 1968 o en la Argentina en 1973, asustó, no caben dudas. En la Argentina asusta cada vezque se peroniza. Por eso, porque la pequeña burguesía intelectual asusta e intranquiliza al agravar "las fragilidades íntimas -dice Milner (La arrogancia...167)- del grupo del que ella es un segmento" fue puesta de rodillas mediante el desmantelamiento de las instituciones que hacían a su reproducción y, en el caso particular de nuestro país, como en el de tantos otros, mediante el exilio, la cárcel y el exterminio. 17 monumentos intranquiliza. En tiempos en los cuales se ha producido un acostumbramiento a las grandes palabras del cine militante, por la vía asintótica al silencio, la película hace corte en la percepción. Más allá del instante que la instala, la mirada como el entendimiento supone una relación con el tiempo. La película causa tedio. En un mundo donde los dueños de la riqueza y su epígonos o imitadores reclaman lo divertido, donde lo divertido es la contracara del aburrimiento, el tedio intranquiliza.

\section{Catorce. A la filosofía de la historia se responde con una política de la historia.}

17 monumentos evita incurrir en las declinaciones narrativas de una filosofía de la historia. Sólo describe la puesta en serie de lugares y monumentos no siempre anudados en una misma coyuntura histórica, acontecimientos algunos distantes en el tiempo cronológico como sucede con las señales-monumentos de los ex CCD y el mojón que remite a las matanzas de la Patagonia en los años '20.

¿La decisión de emplazar señales en lugares de muerte lejanos en el tiempo supone una continuidad histórica, política o epistemológica entre esas prácticas de muerte? Sí y no. Si hay continuidades, y discontinuidades, habrá que sopesarlas en el caso por caso. La interpretación es parte de las pasiones que habitan una política de la historia y por eso no debe presuponerse apriori que las matanzas de la Patagonia y las desapariciones de la última dictadura militar son momentos particulares de un mismo proceso. Decir que sí forman parte de una misma secuencia histórica, y hacerlo aposteriori de analizar sus eventuales conexiones vitales, sí es una conclusión posible. Sólo a título de ejemplo, Marcelo Musante, Alexis Papazián y Pilar Pérez en un trabajo sobre experiencias concentracionarias a las que fueron sometidos los pueblos indígenas, arqueologizan históricamente viejas prácticas de detención y concentración del ejército argentino que, aún soterradas, forman parte del acervo constitucional de esa institución y, por lo tanto, habilitan conjeturar filiaciones operativas entre la conquista de la Patagonia y el

Revista Iberoamericana, Vol. LXXXI, Núm. 251, Abril-Junio 2015, 657-668 ISSN 0034-9631 (Impreso)

ISSN 2154-4794 (Electrónico) 
Chaco y lo sucedido en la última dictadura militar o incluso antes, en Tucumán, durante el gobierno de Isabel Perón.

Quince. La duración, lo que vemos y los que nos mira del pasado reciente.

17 monumentos hace memoria en el acto de la mirada, mirar y, a través de la mirada, imaginar algo acerca de ese pasado reciente y no reciente, imaginarlo en las ruinas o los restos materiales de los ex CCD. La ruina, dice Wajcman, "es un menos-de-objeto que lleva un un-más-de-memoria"(15).

Perel, al formalizar el tiempo de cada cuadro, hace pensar en la duración de la mirada. ¿Cómo incluir la duración en la mirada? ¿De qué manera la mirada hace su trabajo de memoria? En la línea de Bergson, la duración es siempre duración de un movimiento, en este caso el movimiento que conecta el pasado con el presente: según Lapoujade, "la duración bergsoniana no hace desaparecer nada, todo lo contrario del tiempo proustiano por ejemplo que hunde los rostros y debilita los espíritus, que hace morir los seres y los yoes que lo han amado. ¿No hay que darle la razón a Heidegger cuando reprocha a Bergson el haber ignorado el carácter irrevocable del pasado?" (9). La duración pereliana, bajo la mascarada naturalista, bajo la luz lánguida cuando no indigna de las horas indistintas, con sol o sin sol, hace durar lo acontecido. Las señalesmonumentos son $-\mathrm{y}$ esto a pesar de los aciertos y desaciertos políticos, estéticos o epistemológicos de quienes las promueven- los efectos de la duración de un momento en el que, incluyendo los extravíos que lo caracterizaron, la política pudo desembragarse de la oscuridad, o dicho de otro modo, apostó - aun a riesgo de grandes malentendidos-a su relación estructural con la verdad (Badiou, El siglo). El pasado reciente señalizado es un pasado trágico, pero también un pasado triste: en 17 monumentos, la tristeza es rueda de la duración.

\section{Dieciséis. Justicia al acontecimiento.}

Leo una respuesta de Badiou a una pregunta presente en el libro Elogio del amor: "Hay algo muy poderoso en el arte y tiene que ver con que le hace justicia al acontecimiento. Se trata, incluso, de una de las definiciones posibles: el arte es aquello que, a nivel del pensamiento, le hace justicia al acontecimiento" (Elogio 16). No sé si las 17 señales se inscriben en lo que concierne al arte, puedo pensar que -a su modo-sí. 17 monumentos, también a su modo, cumple al pie de la letra con justipreciar 17 lugares de memoria, hacer lugar a 17 acontecimientos siniestros del pasado. 
Diecisiete. No dejarse encerrar en la desesperación.

En El nombre del rey de Asiné, un ensayo sobre el poema que Seferis escribió entre 1938 y 1940, Yves Bonnefoy dice "Y a pesar de esa tristeza cuyas causas son evidentes, ¿no es preciso recordar que la poesía -que aquí está muy presente- raras veces se deja encerrar en la desesperación?" (41). Si es que el amor, como dice Badiou (Elogio), es también un procedimiento de verdad, el acto de memoria que hace florecer 17 monumentos -desde el momento que incita a hablar sobre cómo inscribir el pasado doloroso- podría llamarse, parodiando el nombre del libro de Pablo Neruda Veinte poemas de amor y una canción desesperada, 17 poemas de amor y una canción no desesperada. O me gusta más desesperada no. En tiempos en que todo urge, la no desesperación posee una potencia política extraordinaria. 17 monumentos le da lugar.

\section{BibLIOGRAFÍA}

Agamben, Giorgio. Signatura rerum. Sobre el método. 2008. Buenos Aires: Adriana Hidalgo Editora, 2009.

Badiou, Alain. El siglo. 2005. Buenos Aires: Manantial, 2009.

y Nicolás Truong. Elogio del amor. 2009. Buenos Aires: Paidós, 2012.

Bonnefoy, Yves. El nombre del rey de Asiné. 2003. Buenos Aires: Colección ensayos/ Huesos de Jibia, 2010.

Bryson, Norman. "La pintura Ch'an: mirando un campo que se dilata". Archipiélago 34-35 (1998): 61-70.

Visión y pintura: la lógica de la mirada. Madrid, Alianza Editorial, 1991.

Cevasco, Rithée. La discordancia de los sexos. Buenos Aires: Ediciones S\&P, 2010.

Derrida, Jacques. La verdad en pintura. 1978. Buenos Aires/Barcelona: Paidós, 2001. Foucault, Michel. La arqueología del saber. 1969. México: Siglo XXI, 1988.

Huot, Hervé. Del sujeto en la imagen. Una teoría del ojo en la obra de Freud. 1987. Buenos Aires: Nueva Visión, 1991.

Lapoujade, David. Potencias del tiempo. Versiones de Bergson. 2010. Buenos Aires: Cactus, 2011.

Lévi-Strauss, Claude. Tristes Trópicos. 1955. Buenos Aires: Eudeba, 1976.

Lis, Jacques. "El espacio de la mirada en pintura". Litoral. Revista de la Edelp 16 (1994): 113-138.

Milner, Jean-Claude. Entrevistas con Fabián Fajnwaks y Juan Pablo Luchelli. Claridad de todo. De Lacan a Marx, de Aristóteles a Mao. 2011. Buenos Aires: Manantial, 2012. La arrogancia del presente. Miradas sobre una década: 1965-1975. 2009. Buenos Aires: Bordes Manantial, 2010.

Las inclinaciones criminales de la Europa democrática. 2003. Buenos Aires: Bordes Manantial, 2007.

Revista Iberoamericana, Vol. LXXXI, Núm. 251, Abril-Junio 2015, 657-668 
El paso filosófico de Roland Barthes. 2003. Buenos Aires: Amorrortu, 2004.

Musante, Marcelo, Alexis Papazián y Pilar Pérez. "Los campos de concentración indígena como espacios de excepcionalidad en la matriz estado-nación-territorio argentino". Prácticas Genocidas y Violencia Estatal en Perspectiva Transdisciplinar. Bariloche: Universidad Nacional de Río Negro, 2013. 66-95.

Perrot, Dominique y Roy Preiswerk. Etnocentrismo e historia. América indígena, África y Asia en la visión distorsionada de la cultura occidental.1975. México: Nueva Imagen, 1979.

Rancière, Jacques. El espectador emancipado. 2008. Buenos Aires: Bordes Manantial, 2010.

Red Federal de Sitios de Memoria (REFESIM). "Sitios de Memoria". Archivo nacional de la memoria. <anm.derhuman.jus.gov.ar/sitios-memoria.html>. 12 junio 2015.

Starobinski, Jean. Las palabras bajo las palabras. La teoría de los anagramas de Ferdinand de Saussure. 1971. Barcelona: Gedisa, 1996.

Wajcman, Gérard. El objeto del siglo. 1998. Buenos Aires: Amorrortu, 2001. 